\title{
From Individualized Treatment of Sickle Cell Pain to Precision Medicine: A 40-Year Journey
}

\author{
Samir K. Ballas
}

\begin{abstract}
In the 1970s, sickle cell pain was treated with trial and error approach by increasing or decreasing the dose of an opioid or switching from one analgesic to another. This approach was controversial with criticism and doubt about its usefulness. Since then, advances in determining the structure of opioid receptors and the role of the CYP450 enzymes in metabolizing opioids revealed that these anatomic and metabolic findings are not the same in all persons, thus explaining the variability in response to opioids among patients. Thus, the "trial and error approach" has a scientific basis after all.
\end{abstract}

Keywords: Sickle cell disease; Pain; Individualized treatment; Personalized medicine; Precision medicine

\section{Introduction}

An infliction in the life expectancy figure of patients with sickle cell disease (SCD) occurred around the middle of the 1970s (Fig. 1). This minimal increase in life expectancy coincided with my appointment at Thomas Jefferson University as the Associate Director of the newly created adult sickle cell center. The number of adults at that time was small and the transition from pediatrics to adult programs was at the age of 18 years. The trickle of patients increased gradually and we were faced with adolescent and young adult African American patients who were in a state of confusion. Stripped from the protective sphere of the pediatric world and the empathy of their pediatric hematologists and the pediatric ancillary staff, they were in a state of fear, anxiety, depression and, worst of all, severe pain. The world of adults was abject, withdrawn, busy, and status oriented. The fact that most patients were barely educated, many without a high school degree, unemployed, mediocre health coverage, and dysfunctional family structure conferred a logarithmic dimension to the problem. Their main hope was

Manuscript accepted for publication March 03, 2016

Cardeza Foundation for Hematologic Research, Department of Medicine, Jefferson Medical College, Thomas Jefferson University, Philadelphia, PA 19107, USA. Email: samir.ballas@jefferson.edu

doi: http://dx.doi.org/10.14740/jocmr2508w to have pain relief.

The steady stream of admissions of patients with acute painful vaso-occlusive crises (VOCs) to the emergency department (ED) and hospital were not welcome by most providers, hospital administration, the house and nursing staffs. There was subtle resentment of the patients that sometimes extended to the hematologists who showed compassion to the patients. Soon labels such as drug addicts, drug-seeking behavior, and hospital hopping and frequent flyer emerged.

Listening to and believing the patients and keeping detailed records of ED and hospital admissions and the analgesics prescribed, revealed that most patients genuinely do not respond to a certain analgesic or a certain dose. Increasing the doses of an analgesic or switching to another drug solved the problem in most patients. Soon it became obvious that management of sickle cell pain should be individualized.

Accordingly and with the approval of the institutional review board (IRB), I issued an identification wallet-sized, plasticized card that was carried by patients and presented to the provider treating their $\mathrm{VOC}$ in the ED, hospital or any other medical facility. Information printed on both sides of the card included: 1) demographic data and a recent photograph; 2) hematological data including reticulocyte count; 3) medical data including the type of SCD, its complications and co-morbidities if present; 4) all medications being taken by the patient and the recommended treatment of VOCs including the name, dose, and the route of administration of the analgesics in question; and 5) my name and contact information for answering questions if needed. It was not expensive to issue these cards. A Polaroid camera available at that time and a laminator were the only equipments needed to issue these cards. Information on the card was revised and updated annually. Details of this endeavor were published in 1990 [1]. With the advent of computerization later on, information on the card was computerized and a printed copy was given to the patient.

Reactions to the implementation of this card were mixed. Patients and their families loved it. The patients were very compliant in carrying it as faithfully as they carry their medical cards. Some providers liked it very much because it facilitated having a concise history about the patients. Others denounced it as a gimmick that would allow patients to abuse the system.

\section{Pharmacology of Opioids}

While this controversy was brewing, interesting developments 


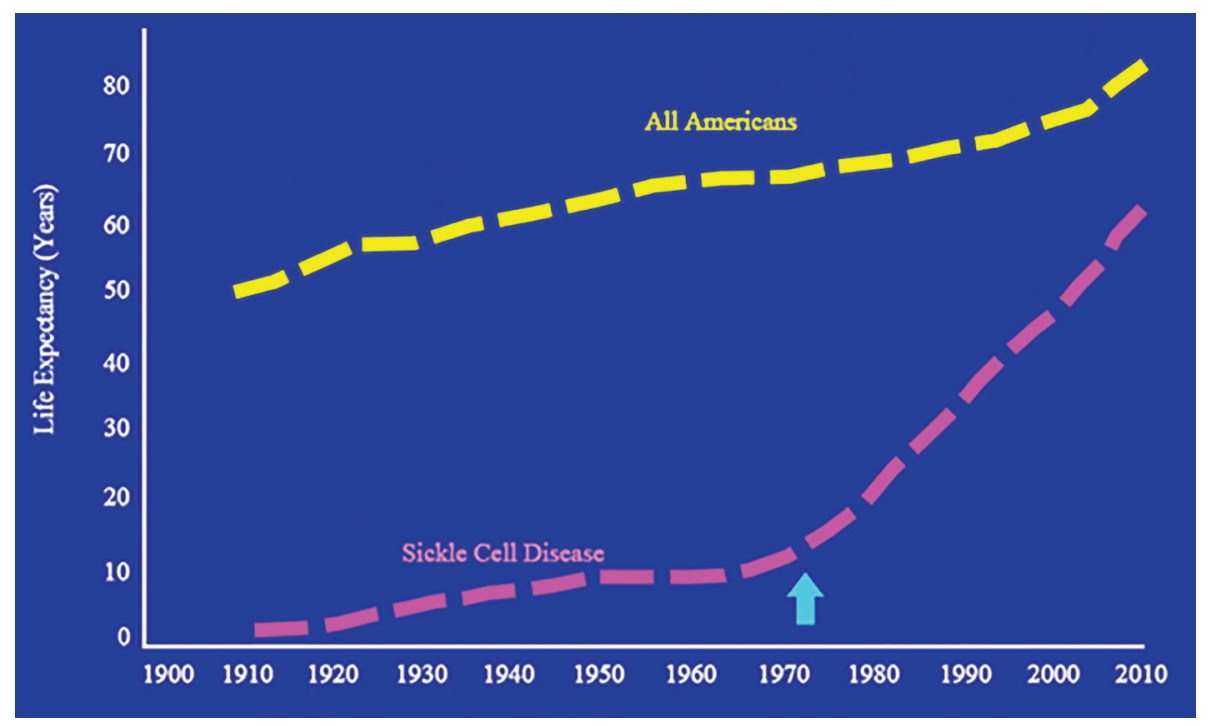

Figure 1. Life expectancy of patients with sickle cell disease from 1900 through 2010. The arrow indicates the infliction point where life expectancy of patients with sickle cell disease began to increase. Adapted from National Heart, Lung, and Blood Institute. Sickle cell research for treatment and cure (NIH Publication No. 02-5214). Bethesda, MD: US Department of Health and Human Services.

in basic science were in progress to understand the pharmacodynamics and pharmacokinetics of opioids. Foremost among these was the mechanism of action of opioids in relieving pain. In the 1970s, it was hypothesized that opioids have receptors to bind to and activate in order to relieve pain [2] by blocking or minimizing the transmission of painful stimuli and raising the pain threshold. It did not take long after that to identify opioids as ligands that bind to stereospecific and saturable receptors in the central nervous system and other tissues [3, 4]. These receptors are transmembranous $\mathrm{G}$ proteins with opioids as ligands [5].

In addition, recent elegant studies [6-10] have revealed a helical structure of the opioid receptors, which forms pockets in which the corresponding opioid (ligand) fits snugly (Fig. 2a, b). Receptors mediate two major functions, chemical recognition and physiologic action. Recognition is highly specific, such that only L-isomers of certain opioids exert analgesic activity [11]. The binding affinity varies considerably among opioids [12]. Fentanyl, for example, has higher binding affinity than morphine [11]. The binding affinities of opioids appear to correlate with their analgesic potencies [13]. Physiologically, by binding to receptors, opioids initiate a series of biochemical events including activation of $\mathrm{G}$ proteins, inhibition of adenylate cyclase, and extrusion of potassium ions, resulting in hyperpolarization of cell membranes [14-16]; this delays or prevents transmission of painful stimuli. Thus, the riddle why some patients respond to one opioid but not another had a pathophysiologic explanation [17].

Parallel to the progress in the pharmacodynamics of opioids mentioned above, a concomitant advance in the pharmacokinetics of opioids was bubbling to the surface. The metabolism of opioids includes two major phases [18, 19].
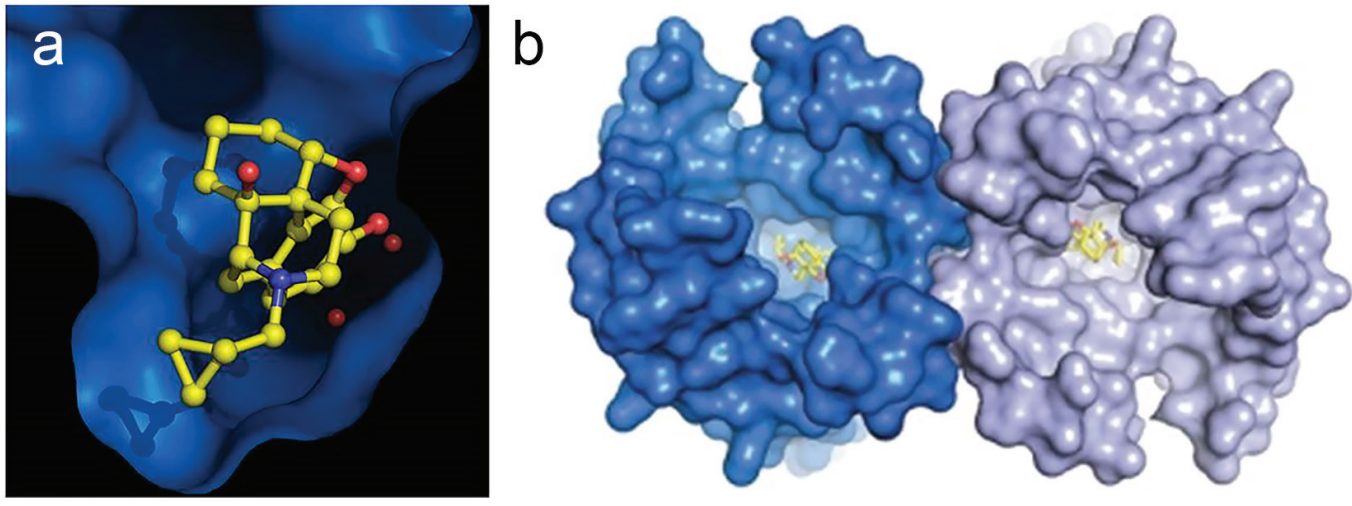

Figure 2. Helical structure of opioid receptors. (a) Morphine-like molecule (yellow) in the deep pocket (blue) of the $\mu$-opioid receptor. (b) $\mu$-Opioid receptors from an intimate pair when crystallized with a ligand (yellow) such as morphine. Knowing how an opioid molecule (yellow) sticks in the pocket of its receptor (blue) could help scientists design better analgesics that are more effective and less addictive. Credit: Kobilka Lab, Nature. 2012;485:321-6. Used with permission. 
Phase I involves the CYP enzymes and phase II metabolism conjugates the drug to hydrophilic substances, such as glucuronic acid, sulfate, glycine, or glutathione. Glucuronidation is the most important phase II reaction. It is catalyzed by the enzyme uridine diphosphate glucuronyltransferase (UGT). Morphine, hydromorphone and oxymorphone are metabolized by glucuronidation, whereas the majority of the other opioids are metabolized by the cytochrome P450 isoenzyme system.

The net effect of an opioid depends on the availability of enzyme(s) to convert it into metabolites that could be active or inactive. Briefly, the CYP2D6 genotypes are categorized into phenotypes based on the activity of the variant enzymes. Ultrarapid metabolizers (UMs) have greater than normal activity due to duplication or triplication, of active alleles [20-23], extensive metabolizers (EMs) have normal enzyme activity, intermediate metabolizers (IMs) have decreased enzyme activity, and poor metabolizers (PMs) have absent or little enzyme activity. Thus, fentanyl, for example, is normally metabolized into inactive metabolites. Patients who are UMs of fentanyl would rapidly convert it into inactive metabolites with minimal or absent analgesic effect requiring increasing the dose of fentanyl. On the other hand, patients who are PMs of fentanyl would experience prompt relief with relatively small doses of fentanyl but higher doses could be toxic due to the accumulation of unmetabolized fentanyl [24]. Phase I metabolism of opioids involves primarily the CYP3A4 and CYP2D6 enzymes. The CYP3A4 enzyme metabolizes more than $50 \%$ of all drugs; consequently, opioids metabolized by this enzyme have a high risk of drug-drug interactions [19].

\section{Conclusion}

Together, current data on the pharmacodynamics and pharmacokinetics of opioids show great variability of genotypes among patients and extreme variability in individual responses to opioids. Determining the pharmacogenetics profile of each patient facilitates the choice of drugs that would be efficacious for that patient and avoid those drugs associated with harmful drug-drug interaction. This approach in diagnostics and therapeutics ushers in the dawn of a new field for the management of individual patients based on their unique pharmacogenetics, phenotypic and biomarker characteristics. This future approach is referred to as personalized medicine or, more recently, precision medicine [25]. It has already been implemented for certain cancer patients receiving chemotherapy. We hope that this methodology would be approved and sponsored by the insurance companies for patients with SCD. In the meantime, listening, believing and respecting the patient with sickle cell pain should be maintained for now as the approach to individualized therapy.

\section{Acknowledgement}

Supported in part by the adult Sickle Cell Program of the Commonwealth of Pennsylvania for the Philadelphia Region.

\section{Conflict of Interest}

The author declares no competing financial interests.

\section{References}

1. Ballas SK. Treatment of pain in adults with sickle cell disease. Am J Hematol. 1990;34(1):49-54.

2. Pert CB, Snyder SH. Opiate receptor: demonstration in nervous tissue. Science. 1973;179(4077):1011-1014.

3. Beckett AH, Casy AF. Synthetic analgesics: stereochemical considerations. J Pharm Pharmacol. 1954;6(12):9861001.

4. Snyder SH. Drug and neurotransmitter receptors in the brain. Science. 1984;224(4644):22-31.

5. Waldhoer M, Bartlett SE, Whistler JL. Opioid receptors. Annu Rev Biochem. 2004;73:953-990.

6. Cox BM. Recent developments in the study of opioid receptors. Mol Pharmacol. 2013;83(4):723-728.

7. Granier S, Manglik A, Kruse AC, Kobilka TS, Thian FS, Weis WI, Kobilka BK. Structure of the delta-opioid receptor bound to naltrindole. Nature. 2012;485(7398):400404.

8. Manglik A, Kruse AC, Kobilka TS, Thian FS, Mathiesen JM, Sunahara RK, Pardo L, et al. Crystal structure of the micro-opioid receptor bound to a morphinan antagonist. Nature. 2012;485(7398):321-326.

9. Thompson AA, Liu W, Chun E, Katritch V, Wu H, Vardy E, Huang XP, et al. Structure of the nociceptin/orphanin FQ receptor in complex with a peptide mimetic. Nature. 2012;485(7398):395-399.

10. Wu H, Wacker D, Mileni M, Katritch V, Han GW, Vardy E, Liu W, et al. Structure of the human kappa-opioid receptor in complex with JDTic. Nature. 2012;485(7398):327332.

11. Leysen JE, Gommeren W, Niemegeers CJ. [3H]Sufentanil, a superior ligand for mu-opiate receptors: binding properties and regional distribution in rat brain and spinal cord. Eur J Pharmacol. 1983;87(2-3):209-225.

12. Kosterlitz WH. Opiate actions in guinea pig ileum and mouse vas deferens. Neurosci Res Bull. 1975:13:68-70.

13. Martin WR, Eades CG, Thompson JA, Huppler RE, Gilbert $\mathrm{PE}$. The effects of morphine- and nalorphine- like drugs in the nondependent and morphine-dependent chronic spinal dog. J Pharmacol Exp Ther. 1976;197(3):517-532.

14. Herz A, Teschemacher HJ. Activities and sites of antinociceptive action of morphine-like analgesics and kinetics of distribution following intravenous intracerebral and intraventricular application. Adv Drug Res. 1971:6:79.

15. Simon EJ, Hiller JM. The opiate receptors. Annu Rev Pharmacol Toxicol. 1978;18:371-394.

16. Snyder SH. Opiate receptors in the brain. N Engl J Med. 1977;296(5):266-271.

17. Ballas SK. Pathophysiology and principles of management of the many faces of the acute vaso-occlusive crisis in patients with sickle cell disease. Eur J Haematol. 2015;95(2):113-123. 
18. Hollenberg PF. Characteristics and common properties of inhibitors, inducers, and activators of CYP enzymes. Drug Metab Rev. 2002;34(1-2):17-35.

19. Smith HS. Opioid metabolism. Mayo Clin Proc. 2009;84(7):613-624.

20. Sery O, Hrazdilova O, Matalova E, Sevcik P. Pain research update from a genetic point of view. Pain Pract. 2005;5(4):341-348.

21. Shord SS, Cavallari LH, Gao W, Jeong HY, Deyo K, Patel SR, Camp JR, et al. The pharmacokinetics of codeine and its metabolites in Blacks with sickle cell disease. Eur J Clin Pharmacol. 2009;65(7):651-658.

22. McGregor LM, Stewart CF, Crews KR, Tagen M, Wozniak A, Wu J, McCarville MB, et al. Dose escalation of in- travenous irinotecan using oral cefpodoxime: a phase I study in pediatric patients with refractory solid tumors. Pediatr Blood Cancer. 2012;58(3):372-379.

23. Neafsey P, Ginsberg G, Hattis D, Sonawane B. Genetic polymorphism in cytochrome P450 2D6 (CYP2D6): Population distribution of CYP2D6 activity. J Toxicol Environ Health B Crit Rev. 2009;12(5-6):334-361.

24. Lotsch J, Skarke C, Liefhold J, Geisslinger G. Genetic predictors of the clinical response to opioid analgesics: clinical utility and future perspectives. Clin Pharmacokinet. 2004;43(14):983-1013.

25. Jameson JL, Longo DL. Precision medicine - personalized, problematic, and promising. $\mathrm{N}$ Engl J Med. 2015;372(23):2229-2234. 